SCIENTIFIC LETTER

\title{
Clinical implications of persistent ST segment depression after admission in patients with non-ST segment elevation acute coronary syndrome
}

\author{
M Kosuge, K Kimura, T Ishikawa, T Shimizu, K Hibi, N Nozawa, S Umemura
}

Heart 2005;91:95-96. doi: 10.1136/hrt.2003.030973

$\mathrm{P}$

atients with non-ST segment elevation acute coronary syndrome (NSTE-ACS) are heterogeneous with regard to both underlying disease and prognosis. ST segment depression on admission in NSTE-ACS is considered a powerful predictor of a poor outcome. ${ }^{1}$ To clarify the clinical significance of ST segment depression, we studied the relation between the change in ST segment depression after admission, to clinical characteristics and angiographic findings in patients with NSTE-ACS.

\section{METHODS}

We studied 190 consecutive patients with NSTE-ACS who had chest pain suggesting cardiac ischaemia within 24 hours before admission, involving an unstable pattern of pain, consisting of rest pain, new onset, severe or frequent angina, accelerating angina, or angina occurring within 21 days after an acute myocardial infarction. A 12 lead ECG was recorded on admission, six hours after admission, and at discharge, at a paper speed of $25 \mathrm{~mm} / \mathrm{s}$ and an amplification of $10 \mathrm{~mm} /$ $\mathrm{mV}$. ST segment depression $\geqslant 1.0 \mathrm{~mm}$ was considered significant. ${ }^{2}$ ST resolution was defined as a reduction of $\geqslant 50 \%$ in the sum of ST segment depression in all leads, except for lead aVR, between ECGs on admission and six hours after admission. On admission, $\mathrm{C}$ reactive protein concentrations were measured by N Latex CRP Mono tests, performed on a Behring BN II Nephelometer (Behring Diagnostics) using polystyrene microbeads coated with monoclonal mouse antibodies; a rapid qualitative assay for cardiac specific troponin $\mathrm{T}$ (Trop $\mathrm{T}$, Roche Diagnostics, detection limit, $0.1 \mathrm{ng} / \mathrm{ml}$ ) was also performed. In patients who were negative for troponin within six hours after the onset of symptoms, the test was repeated at 8-12 hours. ${ }^{3}$ In all patients, cardiac catheterisation was performed a median of four days after admission, excluding urgent cardiac catheterisation. In patients with a single defined culprit lesion, the details of the lesion (morphologic characteristics ${ }^{4}$ and presence of thrombus) and the thrombolysis in myocardial infarction (TIMI) flow grade and myocardial blush grade ${ }^{5}$ were examined. All ECG and angiographic findings were evaluated by two blinded observers.

The study end point was the composite of death, myocardial (re)infarction, or refractory angina (despite aggressive medical treatment, leading to urgent target vessel revascularisation, including percutaneous coronary intervention or coronary artery bypass graft surgery) within 30 days after admission.

Analysis of variance was used for continuous variables. If significance was indicated by analysis of variance, a Bonferonni correction was used as a post hoc test for multiple comparisons. Categorical variables were compared

Table 1 Baseline characteristics

\begin{tabular}{|c|c|c|c|}
\hline & $\begin{array}{l}\text { Group A } \\
(n=61)\end{array}$ & $\begin{array}{l}\text { Group B } \\
(\mathrm{n}=73)\end{array}$ & $\begin{array}{l}\text { Group C } \\
(n=56)\end{array}$ \\
\hline Age (years) & $61(10)$ & †67 (11) & †68 (10) \\
\hline Men & $41(67 \%)$ & $55(75 \%)$ & $33(59 \%)$ \\
\hline Prior MI & $8(13 \%)$ & *23 (32\%) & $+21(38 \%)$ \\
\hline Prior $\mathrm{PCl}$ or $\mathrm{CABG}$ & $5(8 \%)$ & *21 (29\%) & $+20(36 \%)$ \\
\hline hs-CRP on admission (mg/dl) & $0.176(0.276)$ & $0.261(0.356)$ & ${ }^{*} 0.508(1.014)$ \\
\hline Positive troponin & $22(38 \%)$ & $32(44 \%)$ & †34 (64\%) \\
\hline$\Sigma \mathrm{ST} \downarrow$ on admission (mm) & & $4.2(4.2)$ & $\$ 6.3(4.6)$ \\
\hline$\Sigma \mathrm{ST} \downarrow 6$ hours later (mm) & & $1.4(1.2)$ & $\S 5.5(4.5)$ \\
\hline$\Sigma \mathrm{ST} \downarrow$ at discharge (mm) & & $0.7(1.0)$ & $\S 1.9(1.0)$ \\
\hline Multivessel disease & $8(13 \%)$ & $+26(36 \%)$ & $\dagger \S 41(73 \%)$ \\
\hline A single defined culprit lesion & $\mathrm{n}=47$ & $n=63$ & $n=42$ \\
\hline Stenosis of $\geqslant 99 \%$ & $3(6 \%)$ & ${ }^{*} 14(22 \%)$ & †‡17 (41\%) \\
\hline Visible thrombus & $3(6 \%)$ & $5(8 \%)$ & $\dagger \S 17(41 \%)$ \\
\hline Complex lesion & $20(43 \%)$ & $33(52 \%)$ & †‡31 (74\%) \\
\hline TIMI 0/1 flow & 0 & $2(3 \%)$ & †7 (17\%) \\
\hline Myocardial blush grade $0 / 1$ & $3(6 \%)$ & $8(13 \%)$ & $\dagger \S 17(41 \%)$ \\
\hline \multicolumn{4}{|l|}{30 day outcome } \\
\hline Death & 0 & 0 & $1(2 \%)$ \\
\hline Myocardial (re)infarction & 0 & 0 & $5(9 \%)$ \\
\hline Refractory angina & $2(3 \%)$ & $5(7 \%)$ & $\dagger \S 17(30 \%)$ \\
\hline Any of the above & $2(3 \%)$ & $5(7 \%)$ & $\dagger \S 19(34 \%)$ \\
\hline
\end{tabular}

Data are presented as the mean (SD) or number (\%) of patients.

$\mathrm{CABG}$, coronary artery bypass graft surgery; hs-CRP, high sensitive $\mathrm{C}$ reactive protein; $\mathrm{Ml}$, myocardial infarction; $\mathrm{PCl}$, percutaneous coronary intervention; $\Sigma \mathrm{ST} \downarrow$, sum of ST segment depression.

${ }^{*} p<0.05, \uparrow p<0.01 \vee$ group $A ; \neq p<0.05 ; \varsigma p<0.01 \vee$ group $B$. 
by $\chi^{2}$ analysis. Differences were considered significant at $\mathrm{p}<0.05$. Multivariate logistic regression analyses were used to examine the determinants of the combined end point of death, myocardial (re)infarction, or refractory angina within 30 days. Odds ratios (OR) and 95\% confidence intervals (CI) were calculated.

\section{RESULTS}

Patients were classified into three groups according to ECG findings on admission: group A, no ST segment depression $(\mathrm{n}=61)$; group B, ST segment depression with ST resolution ( $\mathrm{n}=73$ ); and group $\mathrm{C}$, ST segment depression without ST resolution $(\mathrm{n}=56)$. The baseline characteristics are shown in table 1. Aspirin, intravenous heparin, and nitrates were used in most patients $(98 \%, 95 \%$, and 98\%, respectively). Hypertension was more frequently observed in groups B and $C$ than in group A $(71 \%, 68 \% \vee 49 \%$, respectively, $\mathrm{p}<0.05$ ), and other coronary risk factors (smoking, hyperlipidaemia, or diabetus mellitus) did not differ. Culprit vessels were similar among the three groups. The rates of multivessel disease, severe stenosis, visible thrombi, complex lesions, and myocardial blush grade of $0 / 1$ indicating impaired myocardial perfusion, and the composite end point were higher in group $\mathrm{C}$ than in groups A and B.

Multivariate analysis identified no ST resolution (OR 8.0, $95 \%$ CI 1.50 to $30.2, p=0.02$ ) and positive troponin (OR 2.2, $95 \%$ CI 1.03 to $4.78, \mathrm{p}=0.04$ ) as independent predictors of the composite end point. The other variables examined, including age, prior myocardial infarction, prior revascularisation, hypertension, multivessel disease, $\mathrm{C}$ reactive protein on admission, and the magnitude of ST segment depression on admission were not significant.

\section{DISCUSSION}

We found that among NSTE-ACS patients with ST segment depression on admission, those with a rapid reduction in the magnitude of ST segment depression after admission had a relatively better outcome at 30 days, similar to patients without ST segment depression. In contrast, patients with persistent ST segment depression six hours after admission had a higher risk of adverse events, probably because of more severe or unstable coronary artery disease (or both). Our results suggest that ST segment analysis, not only on admission, but also after admission, can play an important role in identifying patients with NSTE-ACS who require more aggressive treatment.

In this study, patients with ST segment depression were older and had a higher prevalence of hypertension and multivessel disease, and a longer history of coronary disease, consistent with the results of previous studies. ${ }^{12}$ These findings suggest that ST segment depression is associated with more extensive coronary artery disease. In addition, this study also showed that persistent ST segment depression after admission was also associated with tighter stenoses, complex lesions, visible thrombus in the culprit lesion, and abnormal tissue level perfusion, as well as the afore mentioned extensive coronary disease.

Recent studies have documented the prognostic importance of the magnitude of ST segment depression in patients with NSTE-ACS. ${ }^{1}$ In this study, patients with persistent ST segment depression had a greater degree of ST segment depression on admission. However, multivariate analysis showed that persistent ST segment depression per se, apart from the magnitude of ST segment depression on admission, was related to adverse outcomes. The magnitude of ST segment depression decreased soon after medical treatment in patients who did not have persistent ST segment depression. Even in patients who had persistent ST segment depression, ST segment depression had decreased by discharge, albeit most of these patients had undergone target vessel revascularisation. These findings suggest that persistent ST segment depression might be, at least in part, caused by reversible myocardial ischaemia. We speculate that in patients with persistent ST segment depression, severe and prolonged myocardial ischaemia refractory to medical treatment, associated with more severe and unstable coronary disease, may have contributed to the lack of ST resolution.

We conclude that ST segment analysis early after admission can facilitate risk stratification in NSTE-ACS. Patients with persistent ST segment depression are likely to benefit maximally from more aggressive medical treatment and coronary intervention.

\section{Authors' affiliations}

M Kosuge, K Kimura, T Ishikawa, T Shimizu, K Hibi, N Nozawa, S Umemura, Division of Cardiology, Yokohama City University Medical Center, Yokohama, Japan

Correspondence to: Dr Kazuo Kimura, Division of Cardiology, Yokohama City University Medical Center, 4-57 Urafune-cho, Minamiku, Yokohama 232-0024, Japan; c-kimura@urahp.yokohama-cu.ac.jp

Accepted 26 February 2004

\section{REFERENCES}

1 Kaul P, Newby LK, Fu Y, et al. PARAGON-B Investigators. Troponin T and quantitative ST-segment depression offer complementary prognostic information in the risk stratification of acute coronary syndrome patients. J Am Coll Cardiol 2003;41:371-80.

2 Kaul P, Fu Y, Chang W, et al. Prognostic value of ST segment depression in acute coronary syndromes: insights from PARAGON-A applied to GUSTO-IIb. J Am Coll Cardiol 2001;38:64-71.

3 Braunwald E, Antmann EM, Beasley JW, et al. ACC/AHA guideline update for the management of patients with unstable angina and non-ST-segment elevation myocardial infarction: a report of the American College of Cardiology/American Heart Association task force on practice guidelines (committee on the management of patients with unstable angina). Circulation 2000;102: $1193-209$.

4 Ambrose JA, Israel DH. Angiography in unstable angina. Am J Cardiol $1991 ; 68: 78 \mathrm{~B}-84 \mathrm{~B}$.

5 Van't Hof AWJ, Liem A, Suryapranata $H$, et al. Angiographic assessment of myocardial reperfusion in patients treated with primary angioplasty for acute myocardial infarction. Circulation 1998;97:2302-6. 